\title{
AMDAR y PCR-extra-rápida para la identificación de la tortuga cabezona Caretta caretta (Testudines: Cheloniidae) utilizando el gen mitocondrial citocromo c oxidasa I (COI)
}

\author{
Daniel Lancheros-Piliego, Javier Hernández Fernández ${ }^{凶}$
}

AMDAR and PCR-Extra-fast for Molecular identification of the loggerhead sea turtle Caretta caretta (Testudines: Cheloniidae) using the mitochondrial gene cytochrome c oxidase I (COI)

\begin{abstract}
We molecularly identified the loggerhead turtle Caretta caretta using high-speed PCR amplification and restriction analysis of mitochondrial DNA. We isolated the DNA from blood from juvenile C. caretta from Don Diego beach (Magdalena; $n=4)$, in Islas Del Rosario (Bolívar; $n=2$ ) in the Colombian Caribbean. By using high-speed PCR amplification of mitochondrial cytochrome c oxidase I (COI), we reduced reaction by one third and obtained fragments of 650 base pairs. We analyzed the amplified IOC product using enzymes HindIII, HpyCH4III and MseI and generated an electrophoretic profile, which compared in silico to other sea turtle species sequences, revealed the loggerhead's specific pattern. We found similarity between $97-99 \%$ with $C$. caretta in five of the BLAST analyzed nucleotide sequences and 92\% in another. We generated a bar code for the sampled turtle information and sequences and stored them in the BOLD database. The methodology described for the identification of C. caretta is a fast and inexpensive procedure that minimizes time and improves PCR specificity.
\end{abstract}

Keywords: Caretta caretta; High-speed PCR; Cytochrome c oxidase I (COI); AMDAR; Barcode.

Edited by Alberto Acosta

Universidad Jorge Tadeo Lozano. Facultad de Ciencias Naturales e Ingeniería. Departamento de Ciencias Naturales y Ambientales. Grupo de investigación "GENBIMOL” Genética, Biología Molecular y Bioinformática, Carrera 4 No. 22-61, Bogotá, Colombia

Received: 03-09-2013 Accepted: 07-11-2013

Published on line: 18-11-2013

Citation: Lancheros-Piliego D, Hernández Fernández J (2013) AMDAR y PCR-extra-rápida para identificación de la tortuga cabezona Caretta caretta (Testudines:Cheloniidae) utilizando el gen mitocondrial citocromo c oxidasa I (COI). Universitas Scientiarum 18(3): 321-330 doi: 10.11144/Javeriana.SC18-3.apit

Funding: Dirección de Investigación, Creatividad e Innovación de la Universidad Jorge Tadeo Lozano.

Electronic supplementary material: N/A

SICI: 2027-1352(201309/12)18:3<321:AYPPIDLTCCCUEGMCCO>2.0.TS;2-D

\section{Introduction}

La tortuga cabezona Caretta caretta (Testudines: Cheloniidae) se distribuye en los océanos del mundo (en latitudes templadas, tropicales y subtropicales). Las principales playas de anidación se encuentran en la península de la Florida en Norteamérica (47.000-90.000 nidos/año en las dos últimas décadas; FWS 2013), en Brasil, Japón, en Grecia en el mar Mediterráneo, en Omán en el mar Arábigo y en la isla de Madagascar en África (Dodd 1988, European Environment Agency 2009). Esta especie también anida y se alimenta en algunas zonas del Caribe colombiano (Ministerio 
del Medio Ambiente de Colombia 2002, CeballosFonseca 2004). Como parte de su ciclo de vida realiza migraciones importantes entre las zonas de alimentación y las playas de anidación valiéndose de las corrientes cálidas en el Océano Atlántico como la Corriente Norecuatorial y la Corriente del Golfo en el Caribe (Dodd 1988, Fitzsimmons et al. 1997, Monzón et al. 2012).

La UICN (2013) cataloga a la tortuga cabezona en peligro A1 de extinción y al igual que las demás especies de tortugas marinas está protegida por leyes nacionales y acuerdos internacionales que pretenden mitigar la disminución de hembras anidantes por causas de origen antrópico (Barreto 2011, SWOT 2012, IUCN 2013). El declive de las poblaciones de esta tortuga en el Caribe colombiano es un fenómeno recurrente (Amorocho 2003, Invemar 2003, Barreto 2011). Ese declive poblacional está ocurriendo debido a factores como comercialización de la carne, los huevos, los caparazones y el aceite de las tortugas para el consumo humano (Rueda 2001, SWOT 2012), a esto se suma la captura incidental por pesquerías industriales y artesanales y la pérdida del hábitat (Eckert et al. 2000, Barreto 2011) y la polución marina (Barreto 2011, SWOT 2012).

El proyecto Barcode of life (código de barras del DNA), es la mayor iniciativa genómica mundial para inventariar la biodiversidad del Planeta (Herbert et al. 2004). En los últimos años se ha convertido en uno de los programas internacionales más importantes para la identificación molecular de gran cantidad de especies (Herbert et al. 2004, Herbert et al. 2003, Hubert et al. 2008). Este proyecto sugiere que un fragmento de $648 \mathrm{pb}$ de la región del gen mitocondrial citocromo c oxidasa subunidad I (COI o cox 1), puede servir como etiqueta molecular, convirtiéndose en un código de barras para la identificación de especies animales (Herbert et al. 2003). Sin embargo, Naro_Maciel et al. (2010) reportaron un fragmento de $815 \mathrm{pb}$ del COI para identificar las siete tortugas marinas que habitan los océanos Atlántico y Pacifico. El gen COI constituye el fundamento de los códigos de barras de DNA debido a que su tasa de mutación permite estudiar la biodiversidad de modo eficiente por que la secuencia de nucleótidos se conserva a nivel intraespecífico y es variable a nivel interespecífico (Hubert et al. 2008). Utilizando esta metodología, a Octubre del año 2013, la página WEB del proyecto tiene un reporte de 2.615.761 códigos de barras que describen 192.670 especies (Sujeevan \& Hebert 2007). El código de barras para especies amenazadas facilita un sistema de identificación de organismos, que permite clasificar de manera rápida, simple y rentable diferentes muestras de especímenes saqueados, comercializados y capturados ilegalmente (Hajibabaei 2012, Naro-Maciel et al. 2010). Esta iniciativa mejora el conocimiento taxonómico, que es clave para el desarrollo de estrategias de conservación adecuadas (DeSalle \& Amato 2004).

La identificación molecular es de gran utilidad en biología de la conservación, en cuanto a censos de biodiversidad y cuando los métodos tradicionales son ineficaces, como en la identificación de huevos, formas larvarias, o en el análisis del contenido del estómago o los excrementos para determinar redes alimentarias (Stoeckle 2003). Además pueden ser potencialmente empleados en casos forenses para identificar muestras de tejidos obtenidos a partir del comercio ilegal o el uso de huevos y la carne (Hajibabaei et al. 2006). Los Códigos de barras de ADN también son aplicables en la investigación de campo para la identificación de los nidos perdidos y tortugas varadas en las playas que con frecuencia se encuentran en un avanzado estado de descomposición, lo que complica la identificación de especies correctamente. Otra posibilidad es la rápida identificación de híbridos interespecíficos, que puede ser tan frecuente, como el $45 \%$ de la población de E. imbricata de Bahía, Brasil (LaraRuiz et al. 2006, Sarah et al. 2009).

Considerando la importancia ecológica y socio-cultural que tiene la tortuga caguama y su afectación por el tráfico ilegal y la pérdida del hábitat, esta investigación tuvo como fin establecer metodología rápida, de bajo costo y efectiva para identificar especímenes de C. caretta utilizando la etiqueta molecular representada por el gen mitocondrial COI. A su vez, se colaboró con la Librería de Códigos de barras documentando la biodiversidad en el Caribe Colombiano. 


\section{Materiales y Métodos}

Obtención de muestras: Se recolectaron muestras de la sangre periférica de dos hembras adultas y cuatro juveniles de $C$. caretta provenientes de dos zonas en el Caribe Colombiano: La playa de anidación Don Diego en zona de influencia del PNNT (N=4), departamento del Magdalena y la isla San Martín de Pajarales en el PNNCRSB, departamento de Bolívar ( $\mathrm{N}=2$ ). Las muestras se obtuvieron a nivel del seno cervical siguiendo la metodología de Dutton (1996) y fueron almacenadas en tubos estériles con solución 0.1 M Tris-EDTA (Greiner Bio-one ${ }^{\circledR}$, Kremsmünster, Austria) para transportarlas en refrigeración hasta el Laboratorio de Biología Molecular de la Universidad Jorge Tadeo Lozano en Bogotá, donde se preservaron a $4^{\circ} \mathrm{C}$.

Extracción de DNA: El DNA genómico se obtuvo utilizando el kit de extracción UltraClean ${ }^{T M}$ Tissue \& Cells DNA Isolates siguiendo el protocolo suministrado por la casa comercial fabricante (MO BIO Laboratories, Inc, California, EE.UU.). Las extracciones fueron reveladas por electroforesis en gel de agarosa al $1 \%$ p/v en solución tampón TBE 0.5X con tinción de bromuro de etidio (2 $\mu \mathrm{g} / \mathrm{ml}$ ) en una cámara horizontal GelXL UltraV-2 (Labnet International, Inc. New Jersey, EE.UU.). El resultado de la separación fue registrado con el fotodocumentador UVP GelDoc-It ${ }^{\mathrm{TM}}$ System (UVP, Upland, EE.UU.) utlizando luz UV y se analizó con el programa Vision Works ${ }^{\circledR} L S$ Image Acquisition and Analysis Software (Imaging system, EE.UU.).

\section{Amplificación del gen mtDNA citocromo $c$ oxidasa I por PCR-Extra rápida: Para amplificar} el gen mtDNA COI citocromo c oxidasa I por PCR Extra-rápida se realizó la reacción como se describe previamente (Liu \& Shearn 1995, Mariño et al. 1996) y se completó un ensayo con el objetivo de disminuir en la PCR los tiempos de denaturación, hibridación y extensión desde 1 minuto hasta 1 segundo cada uno. Fueron utilizados los primers-oligonucleótidos heterológos VF2 (5'-TCAACCAACCACAAAGACATTGGCAC-3') y VR1 (5'-TAGACTTCTGGGTGGCCAAAGAATCA-3'), publicados previamente (Ward et al. 2005, Ivanova et al. 2007) y diseñados para amplificar el gen COI en la tortuga Chelonia mydas (Wang et al. 2012). La reacción de PCR Extra-rápida se realizó utilizando el termociclador de bloque PTC- $100^{\text {TM }}$ Programmable Thermal Controller (MJ Research, Madison, EE.UU.) en mezclas de reacción con volumen final de $25 \mu$, las cuales contenían cada una 20 ng de DNA, $0.5 \mathrm{mM}$ de cada primer-oligonucleótido, 1.5 $\mathrm{mM} \mathrm{MgCl} 2,1 \mathrm{U}$ de Taq Polimerasa (Bioline Inc., California, EE.UU.), $200 \mathrm{mM}$ de cada dNTP's (Bioline Inc., California, EE.UU.) y solución PCRtampón 1X $(50 \mathrm{mM} \mathrm{KCl}$ y $10 \mathrm{mM}$ Tris- $\mathrm{HCl} \mathrm{pH}$ 8,3). Los parámetros de amplificación incluyeron desnaturalización 2 min a $94^{\circ} \mathrm{C}$, seguida por 35 ciclos de $94^{\circ} \mathrm{C}$ por $1 \mathrm{~s}, 53^{\circ} \mathrm{C}$ por $1 \mathrm{~s} \mathrm{y} 72^{\circ} \mathrm{C}$ por $1 \mathrm{~s}$, finalizando con una extensión de $10 \mathrm{~min}$ a $72^{\circ} \mathrm{C}$.

Para determinar la calidad de los productos de la PCR Extra-rápida, $2 \mu \mathrm{l}$ de cada amplificado fueron mezclados con el mismo volumen de tampón de carga (30 \% Glicerol y $0.05 \%$ Azul de bromofenol $\mathrm{p} / \mathrm{v}$ ) y esta mezcla se sirvió en los pozos de un gel de agarosa al $1 \%(\mathrm{p} / \mathrm{v})$ en TBE $0,5 \mathrm{X}$. El gel fue teñido con bromuro de etidio (2 $\mu \mathrm{g} / \mathrm{ml})$. La amplificación del gen COI de C. caretta fue verificada evidenciando en el gel la presencia de una única banda de 650 pares de bases (bp) utilizando el marcador de peso molecular Hiperladder II (Bioline Inc., California, EE.UU.). El proceso fueregistrado con el fotodocumentador UVP Gel-Doc-IT ${ }^{\mathrm{TM}}$ System (UVP, Upland, EE.UU.) y analizado con el programa Vision WorksLs (Imaging system, EE.UU.).

Purificación de los productos de la PCR Extrarápida: Un volumen de $23 \mu \mathrm{l}$ de cada uno de los productos amplificados de COI por PCR Extrarápida fue corrido por electroforesis bajo las mismas condiciones en que se verificó la amplificación inicial. Las bandas del producto se cortaron del gel de agarosa y se purificaron con el kit Ultra Clean $^{\circledR}$ Gel Spin $^{\circledR}$ DNA Extraction siguiendo las instrucciones de la casa comercial fabricante (MO BIO laboratorios, Inc. California, EE.UU.).

Secuenciación del COI de C. caretta: Para obtener la secuencia nucleotídica del gen COI de C. caretta, $25 \mu \mathrm{l}$ de cada uno de los productos purificados de la PCR Extra-rápida junto con los 
oligonucleótidos VF2 y VR1 fueron secuenciados automáticamente en ambas direcciones (5'3' y 3'-5') utilizando el método tagDye Deoxy Terminator Cycle-sequencing en un secuenciador 3730XL (Applied Biosystems).

Análisis in silico y experimental por AMDAR del gen mtDNA COI: Se realizó un análisis AMDAR (Amplificación Mitocondrial de DNA y Análisis de Restricción) in silico con datos de secuencias del gen COI de tortugas de la familia Cheloniidae previamente publicados en las bases de datos BOLD-MAS (http://www.boldsystems. org/views/login.php) y GENBANK (http:// www.ncbi.nlm.nih.gov; Tabla 1) utilizando las enzimas de restricción HindIII, HpyCH4III y MseI. Para este análisis se utilizó la herramienta en línea NEBcutter V2.0 (http://tools.neb. com/NEBcutter2/index.php de New England BioLabs $^{\circledR}$, Inc. Ipswich, EE.UU.) la cual permite utilizar enzimas de restricción para cortar una secuencia de DNA y finalmente generar mapas de restricción corriendo una electroforesis virtual y producir el perfil de cada especie (Vincze et al. 2003). Estas huellas moleculares obtenidas in silico fueron utilizadas para hacer comparaciones con el análisis AMDAR in vitro obtenido experimentalmente.

Para obtener in vitro la huella dactilar del gen mtDNA COI de C. Caretta se realizaron cuatro restricciones enzimáticas sobre el producto de amplificación obtenido por PCR Extra-rápida utilizando las mismas enzimas que en el análisis in silico y siguiendo el protocolo de la casa comercial fabricante (INVITROGEN CORP, California, EE.UU.). Las enzimas fueron utilizadas para cortar individualmente y en conjunto los amplicones del gen COI y los perfiles producidos fueron revelados en gel de agarosa al $2 \% \mathrm{p} / \mathrm{v}$. El proceso fue registrado con el fotodocumentador UVP Gel-Doc-ITT ${ }^{\mathrm{TM}}$ System (UVP, Upland, EE.UU.) y análizados con el programa Vision WorksLs (Imaging system, EE.UU.).

La información generada en ambos procedimientos fue analizada de acuerdo a la cantidad de bandas y el peso molecular de los fragmentos de corte que se produjeron.

Generación del código de barras: Las secuencias obtenidas por PCR Extra-rápida del gen mtDNA COI de C. caretta fueron ensambladas con el programa CLC DNA WorkBench 5.6.1 (CLC Bio, Dinamarca). La comparación e identificación a nivel de género y especie de cada una de las secuencias fue realizado con la herramienta de Búsqueda de Alineamiento Básico Local, BLAST (Altschul et al. 1997).

\section{Resultados y Discusión}

El DNA genómico aislado a partir de las muestras de sangre de las seis tortugas procedentes del Caribe colombiano fue viable, obteniéndose concentraciones entre $80-95 \mu \mathrm{g} / \mathrm{ml}$. Por su parte,

Tabla 1. Descripción de las especies y número de acceción a GenBank de las secuencias del gen COI de tortugas marinas previamente descritas en bases de datos y utilizadas para el análisis AMDAR in silico de identificación de la tortuga cabezona Caretta caretta.

\begin{tabular}{lcccc}
\hline & Unidad taxonómica & Ubicación geográfica & Accesión GenBanK & Autor \\
\hline Chelonia mydas & $\mathrm{Cm}$ & USA & GQ152881 \\
\hline Dermochelys coriacea & $\mathrm{Dc}$ & Australia & $\mathrm{GQ152876}$ & Naro-Maciel \\
Eretmochelys imbircatta & $\mathrm{Ei}$ & Puerto Rico & $\mathrm{GQ} 152887$ & et al., 2010 \\
Lepidochelys kempii & $\mathrm{Lk}$ & $\mathrm{USA}$ & $\mathrm{GQ152891}$ & $\mathrm{GC152890}$ \\
Lepidochelys olivacea & $\mathrm{Lo}$ & Australia & $\mathrm{GQ152883}$ \\
\hline Natator depressa & $\mathrm{Nd}$ & Australia & \\
\hline
\end{tabular}


las amplificaciones del gen COI realizadas por PCR Extra-rápida mostraron una buena resolución en la electroforesis con bandas de 648 bp (Figura 1). Estos productos amplificados se utilizaron seguidamente, en análisis de restricción enzimática y posteriormente en secuenciación.

La amplificación de fragmentos del gen COI de la tortuga $C$. caretta por PCR Extra-rápida se obtuvo en un tiempo record de 74 minutos, reduciendo el tiempo de amplificación a $1 / 3$ con respecto al tiempo convencional requerido. Generalmente el tiempo requerido para una reacción de amplificación estándar es de 3-4 horas o un poco más, con tiempos de denaturación, hibridación y extensión de 1 minuto cada uno (Saiki et al. 1998). El análisis de costo aproximado de una reacción de PCR y su revelado sin pagar el técnico y el uso de instalaciones y equipos es de \$1.2 US. Este avance en la técnica hace posible amplificar de manera eficiente muestras de DNA de la tortugas cabezona.
Identificación molecular por AMDAR del gen mitocondrial COI: Se realizó un análisis AMDAR (Amplificación Mitocondrial de DNA y Análisis de Restricción) in silico utilizando secuencias del gen mitocondrial COI de las siete especies de tortugas marinas realizando restricción con las enzimas HindIII, HpyCH4III y MseI. El objetivo del análisis fue identificar las secuencias a nivel de especie mediante la obtención de patrones de bandeo in silico distintivos para cada taxón. Los perfiles electroforéticos obtenidos del gen COI para las siete especies de tortugas marinas mostraron diferencias observables, que permitían en principio la identificación de Caretta caretta (Figura 2a). Se obtuvieron como resultado cinco patrones de bandeo diferentes al analizar los polimorfismos en la longitud de los fragmentos de restricción para las 7 tortugas evaluadas (Figura 2a). Dos de estos perfiles electroforéticos fueron compartidos por dos especies cada uno y los otros tres perfiles fueron únicos para las especies C. caretta, L. kempii y D. coriacea. Para $C$.

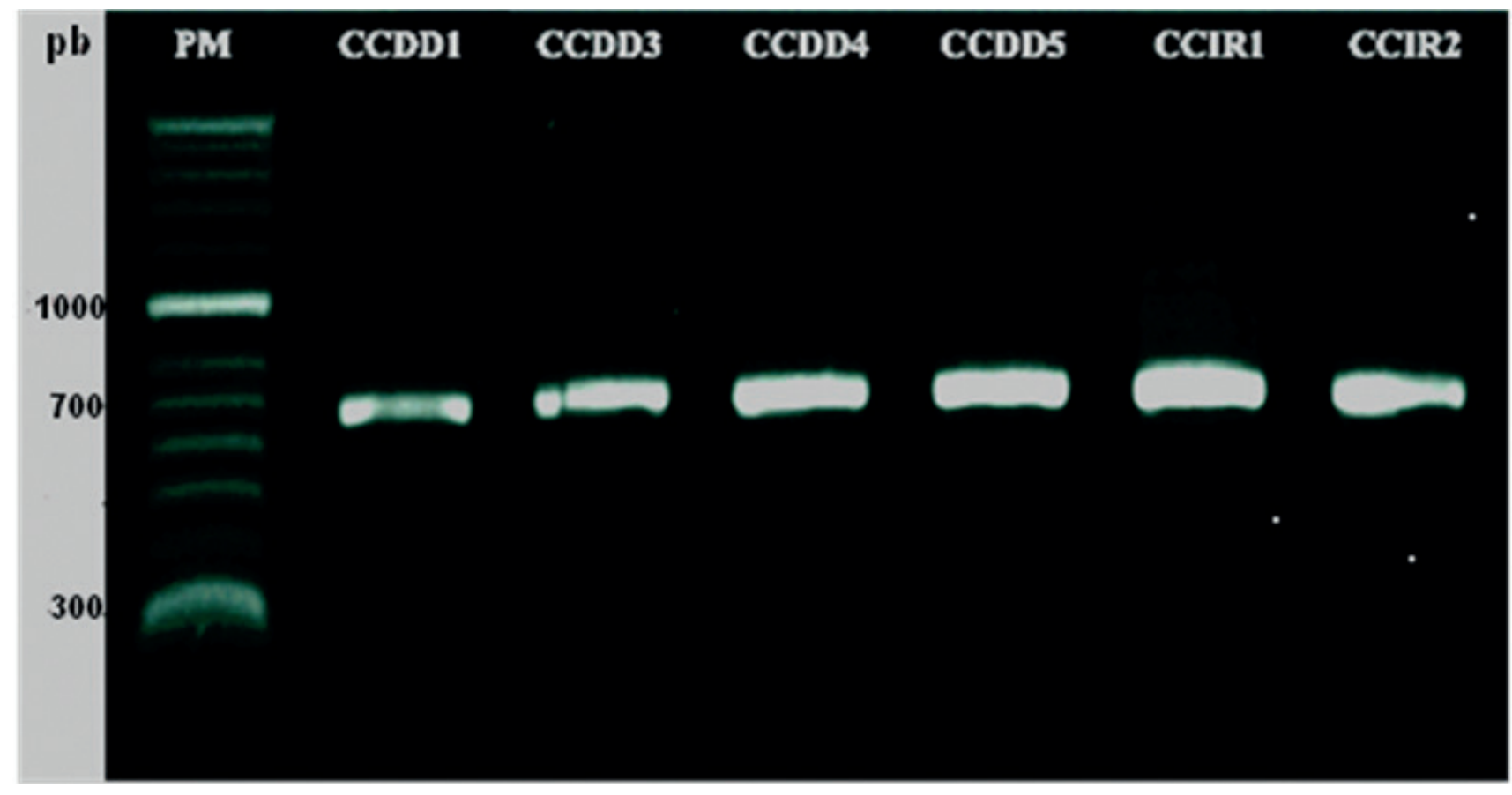

Fig. 1. Productos de amplificación del gen citocromo c oxidasa I (COI) por PCR Extra-rápida de 6 especímenes de la tortuga marina Caretta caretta utilizando los primers VH1 y VR2. En los seis carriles se observa una banda nítida con un tamaño aproximado de 648 pares de bases que corresponde al fragmento esperado para el gen COI. PM: Marcador de peso molecular Hiperladder II (Bioline Inc., California, EE.UU.). Electroforesis en gel de agarosa al $1 \%$, teñido con bromuro de etidio. 
caretta los fragmentos de restricción obtenidos fueron de 228, 147, 139, 76 y 48 pb. Para L. kempii fueron de 458, 179, 82 y $15 \mathrm{pb}$ y para $D$. coriacea fueron de 274, 194, 103 y 82 pb. Por su parte $C$. mydas y $N$. depressus obtuvieron idéntico patrón electroforético revelando fragmentos de 335, 194, 103 y $82 \mathrm{pb}$. De la misma forma E. imbricata y L. olivacea obtuvieron idéntico patrón de restricción mostrando fragmentos de 458, 194 y $82 \mathrm{pb}$.

El AMDAR in vitro realizado con los productos amplificados del gen COI de C. caretta por PCR Extra-rápida con una mezcla de las enzimas HindIII, HpyCH4III y MseI produjo un perfil electroforético con los fragmentos de restricción predichos por el análisis AMDAR in silico, conformado por cuatro bandas con pesos de 228, 147, 139 y 76 pb aproximadamente (Figura 2b).

Identificación molecular por código de barras: Se obtuvieron las secuencias nucleótidicas de cada uno de los amplicones. Mediante análisis con BLAST se detectó para las seis secuencias la filiación comparando con secuencias previamente descritas para Caretta caretta en GenBank y BOLD, la composición media de Guanina y Citocina (GC) fue del $44.99 \% \pm 0.489$.

En el análisis de similitud realizado con el Motor taxonómico de BOLD, las secuencias mostraron niveles altos de homologías con códigos de barras de tortugas marinas previamente registrados en la base de datos. Las secuencias nucleótidicas de las seis muestras fueron identificadas como pertenecientes a la especie Caretta caretta con valores de similitud porcentual altos (>97).

Los sitios variables en las secuencias del mismo gen se acumulan de manera natural en el genoma de los organismos y su estudio se ha modelado matemáticamente para ilustrar y explicar la evolución de las mutaciones en las secuencias de nucleótidos de DNA. La divergencia media intraespecífica, calculada como la cantidad de
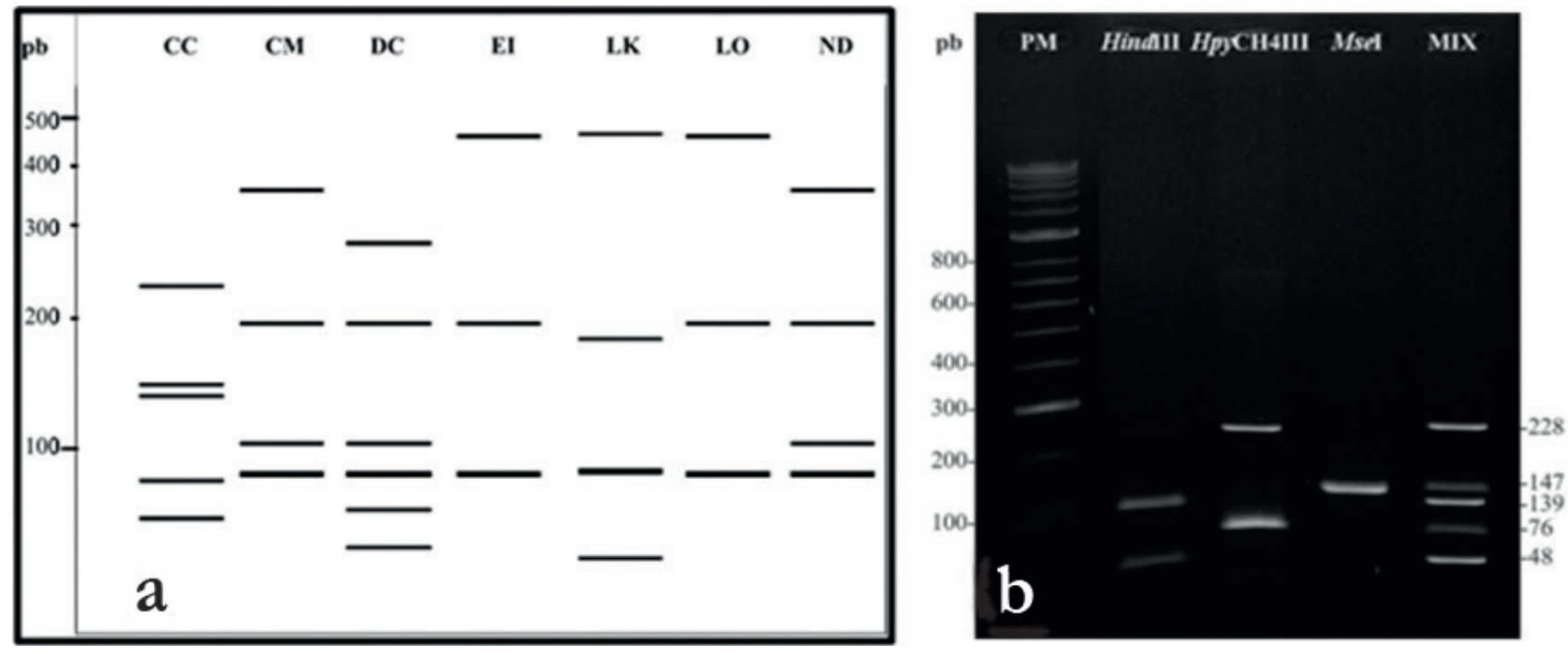

Fig. 2. a. Perfiles de restricción por AMDAR-in silico del gen mtDNA COI para las siete especies de tortugas marinas existentes. Las enzimas de restriccion HindIII, HpyCH4III y MseI producen un patrón de bandeo específico para C. caretta, L. kempii y D. coriacea. Carril Cc: C. caretta; Carril Cm: Chelonia mydas; Dc: Dermochelys coriacea; Ei: Eretmochelys imbricata; Lk: Lepidochelys kempii; Lo: Lepidochelys olivacea y Nd: Natator depressus. Las secuencias del gen COI se obtuvieron en GenBanK (http://www.ncbi.nlm.nih.gov/). b: AMDAR-in vitro del fragmento amplificado por PCR extra-rápida del gen mitocondrial citocromo c oxidasa I (COI) con las enzimas HindIII, HpyCH4III y MseI y una Mix utilizando las tres enzimas. Los carriles cc en A con la MIX en $\mathrm{B}$ muestran las mismas bandas, comparación que permite identificar a la tortuga cabezona. PM: Marcador de peso molecular Hyperladder II (Bioline, UK). Electroforesis en gel de agarosa-1 \% (p/v), TBE 0,5 X teñido con bromuro de etidio. 
posiciones variables encontrada sobre el número total de posibles cambios fue $0.036 \%$ (Tabla 2) cifra inferior al 0,9\% encontrado por Naro-Maciel et al. (2010) para Caretta caretta en la costa de Brasil, y por otra parte, la divergencia media interespecífica con respecto a $L$. olivacea, (la especie más cercana según el análisis de COI) fue del 7,2 \% comparado con 6,3\% reportado por Sarah et al. (2009).

Tabla 2. Distancia K2P (Parámetro 2 de Kimura) de las secuencias del gen mtDNA COI de la tortuga Caretta caretta obtenidas en este estudio. CCDD: Espécimen colectado en playa Don Diego (Magdalena), CCIR: Espécimen recolectado en Islas del Rosario (Cartagena).

\section{CCDD1 CCIR1 CCDD3 CCDD4 CCDD5 CCIR2}

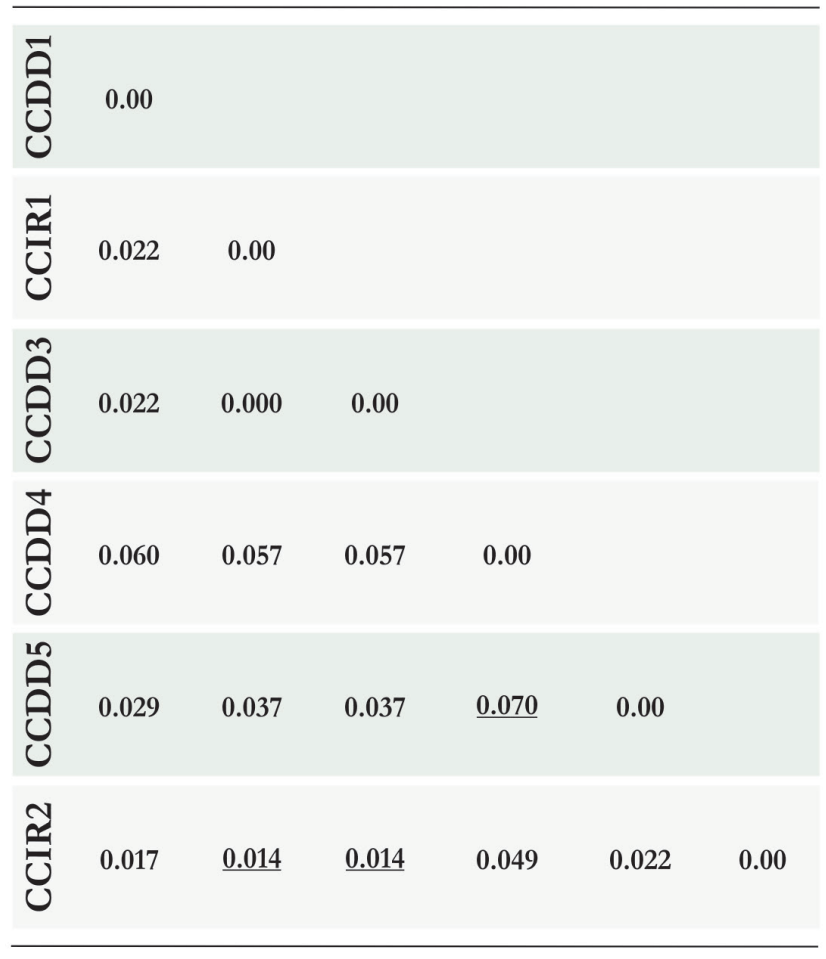

Los códigos de barras del gen mitocondrial citocromo c oxidasa I se fundamentan en el escaso grado de variabilidad nucleótidica que existe a nivel intraespecífico comparado con una mayor variabilidad al nivel interespecífico (Hubert et al. 2008).

Para lograr hacer comparaciones directas de loci homólogos en el área de distribución global de las tortugas marinas, los laboratorios en el mundo deben utilizar los mismos juegos de primers o iniciadores oligonucleótidos para la amplificación por PCR del gen mtDNA COI (Allard et al. 1994, Dutton 1996, FitzSimmons et al. 1997). En este caso y con los cebadores seleccionados los códigos de barras discriminaron los especímenes de $C$. caretta de las demás especies de tortugas marinas y claramente abren la posibilidad de evaluar su utilidad para identificar específicamente huevos, neonatos, juveniles y adultos así como carne, aceite, piel, huesos y caparazones para evitar la depredación y el tráfico ilegal de esta especie.

Las secuencias del COI para las seis tortugas evaluadas se registraron en la base de datos de BOLD Systems con los números de acceso CCOL001-10 a CCOL006. Con los datos de las secuencias y el análisis de las distancias se desarrolló el código de barras de la tortuga $C$. caretta permitiendo su caracterización hasta el nivel de especie en forma confiable y rápida. Este resultado concuerda con diversos estudios del gen COI en tortugas marinas (Sarah et al. 2009, NaroMaciel et al. 2010) y en diversos grupos animales (Herbert et al. 2004, Hubert et al. 2008, Sinniger et al. 2008, Schander \& Willassen 2005).

Una vez que la base de datos global de códigos de barras de COI sea establecida completamente para tortugas marinas cualquier persona con acceso directo o indirecto a secuenciación de DNA será capaz de identificar, con un alto grado de veracidad, cualquier individuo, huevo, caparazón, carne, huesos y aceite. Esta será una herramienta invaluable para los conservacionistas, las pesquerías y los gobiernos. La totalidad de la información generada por esta técnica se encuentra almacenada en la Base de Datos de Códigos de Barras de la Vida -BOLD- y es de libre acceso.

\section{Conclusión}

El gen COI puede ser amplificado por PCR Extra rápida y es un marcador molecular idóneo para la identificación específica de la tortuga cabezona Caretta caretta. El proceso taxonómico puede ser abordado de dos maneras tras conseguir las amplificaciones de COI: Primero el patrón de bandeo obtenido con AMDAR utilizando las 
enzimas HindIII, HpyCH4III y MseI presentó una huella dactilar que diferenció a $C$. caretta de las demás especies de tortugas marinas en análisis computacionales y es una metodología rápida y económica. El proceso de secuenciación presentó información suficiente para generar el código de barras y es una herramienta útil que ofrece la posibilidad de estudiar la diversidad en el grupo de los Chelonios marinos. Antes de este estudio no estaban disponibles métodos analíticos precisos en Colombia que permitieran identificar esta especie amenazada, este estudio contribuye proporcionando una herramienta para el avance de las investigaciones científicas y los programas de conservación de la especie en el Caribe colombiano, creando la necesidad de evaluar la utilidad de los marcadores AMDAR y Código de barras del gen mtDNA COI para la identificación taxonómica de muestras de otro tipo de tejidos de neonatos, juveniles y adultos, así como huevos y productos derivados de la especie.

Con el método descrito en esta investigación la identificación de la tortuga marina $C$. caretta se convierte en un procedimiento rutinario, rápido y de costo efectivo ya que no precisa de taxónomos especializados para obtener resultados confiables y puede ser ultimado en pocas horas tras la obtención de las muestras.

\section{Agradecimientos}

Agradecemos al Oceanario CEINER en la isla de St. Martin Pajarales y al Acuario y Museo del Mar en Santa Marta Rodadero para la colaboración en la obtención y suministro de muestras de la tortuga cabezona Caretta caretta para el desarrollo de este estudio. A la Dirección de Investigación, Creatividad e Innovación de la UJTL por la financiación. Las muestras fueron obtenidas bajo permiso de investigación concedido por el Ministerio de Medio Ambiente y Desarrollo Territorial ( ${ }^{\circ}$ 24, de 22 de junio de 2012) y el Contrato de Acceso a los Recursos Genéticos $\left(\mathrm{N}^{\circ}\right.$ 64, de 23 de abril de 2013).

\section{Conflicto de intereses}

Los autores declaran que no tienen conflicto de intereses.

\section{Referencias}

Allard M, Miyamoto M, Bjorndal K, Bolten A, Bowen B (1994) Support for natal homing in green turtles from mitochondrial DNA sequences. Copeia 1:34-41

Amorocho D (2003) Monitoring nesting loggerhead turtles (Caretta caretta) in the central caribbean coast of Colombia. Marine turtle newsletter 101:8-13

Altschul SF, Madden TL, Schaffer AA, Zhang J, Zhang Z, Miller W, Lipman D J (1997) Gapped BLAST and PSI-BLAST: A new generation of protein database search programs. Nucleic Acids Research 25:33893402. Available at http://www.ncbi.nlm.nih.gov/ BLAST/

Barreto L (2011) Diagnostico del estado actual de las tortugas en el Pacifico colombiano. Informe de País. Fundación Conservación Ambiente Colombia. http://www. natura.org.co/estacion-septiembre/ver-categoria. html. Consultado Octubre de 2013

Ceballos-Fonseca C (2004) Distribución de playas de anidación y áreas de alimentación de tortugas marinas y sus amenazas en el Caribe colombiano. Boletin de Investigaciones Marinas y Costeras, INVEMAR 33:79-99

Desalle R \& Amato G (2004) The expansion of conservation genetics. Nature Reviews Genetics 5:702712 doi:10.1038/nrg1425

Dodd CK Jr (1988) Synopsis of the biological data on the loggerhead sea turtle Caretta caretta (Linnaeus 1758). Fish and Wildlife Service Biological Report 88(14):110 p.

Dutton P (1996) Methods for collection and preservation of samples for sea turtle genetic studies. In: Bowen BW and Witzell WN (Eds) Proceedings of the International Symposium on Sea Turtle Conservation Genetics, Miami FL, 12-14 Sept. 1995. Miami, Florida: NOAA Technical Memorandum NMFS-SEFSC-396:17-24

Eckert K (2000) Diseño de un programa de conservación. 6-8. En: Eckert, K., K. Bjorndal, F. Abreu-Grobois FA, Donnelly M (Eds.). Técnicas de investigación y manejo para la conservación de tortugas marinas. Grupo especialista en tortugas marinas UICN/CSE, México. 278 p.

European Environment Agency (2009) Caretta caretta Assessemts of conservation status at the European level. in: Habitat Directive Article 17 Reporting. Copenhagen: European Environment Agency 13(7):2

Fitzsimmons N, Moritz G, Limpus C, Norman J, Goldizen A, Miller J (1997) Philopatry of male marine turtles inferred from mitochondrial DNA markers. Procedings of the National Academy of Science of the United State of America 94(16):8912-7 
FWC (2013) A statistical analysis of trends in Florida's loggerhead nest counts with data through 2012. Florida Fish \& Wildlife Conservation Commission. http://myfwc. com/research/wildlife/sea-turtles/ nesting/loggerhead-trends/ [revisión, Febrero 2013]

Hajibabaei M (2012) The golden age of DNA metasystematics. Trends in Genetics. 28:535-537. doi: 10.1016/j.tig.2012.08.001

Hajibabaei M, Smith A, Janzen D, Rodriguez J, Whitfield J, Hebert PA (2006) minimalist barcode can identify a specimen whose DNA is degraded. Molecular Ecology Notes 6:959-964

Hebert P, Cywinska A, Ball S, deWaard J (2003) Biological identifications through DNA barcodes. Proceedings of the Royal Society of London. Series B, Biological Sciences 270:313-322

Hebert P, Stoeckle M, Zemlak T, Francis C (2004) Identification of Birds Through DNA Barcodes. PLoS Biology 2(10):1657-1663

Hubert N, Hanner R, Holm E, Mandrak NE, Taylor E (2008) Identifying Canadian Freshwater Fishes through DNA Barcodes. PLoS ONE 3(6):e2490 doi:10.1371/journal.pone. 0002490

Invemar (2003) Distribución, amenazas y esfuerzos de conservación de las tortugas marinas en el Pacífico colombiano. Informe final, Santa Marta, Colombia $78 \mathrm{p}$.

IUCN (2013) Lista Roja de Especies Amenazadas. Versión 2013.1. ( www.iucnredlist.org). Consultado el 23 de octubre 2013

Ivanova N, Zemlak T, Hanner R, Hebert P (2007) Universal primer cocktails for fish DNA barcoding. Molecular Ecology Notes 7:544-548

Lara-Ruiz P, López GG, Santos FR, Soares LS (2006) Extensive hybridization in hawksbill turtles (Eretmochelys imbricata) nesting in Brazil revealed by mtDNA analyses. Conservation Genetics 7:773-781

Liu LZ, Shear A (1995) Rapid PCR for RNA Differential Display in a conventional Heat Block thermal Cycler. Biotechniques 19:44-46

Mariño-Ramírez L, Hernández-Fernández J, OrozcoCárdenas ML, Narváez-Vásquez J (1996) Caracterización Molecular de Genes cry de Bacillus thuringiensis utilizando PCR Extra-Rápida. Revista Corpoica 1:47-47

Monzón C, Dell'Amico F, Morinière P, Marco A, López-Jurado LF, Hays GC, Scott R, Marsch R, Lee P (2012) Lost at the sea: genetic, ocanoOAG_ PSTB/2013.1113 Geographic and meteorological evidence for storm-forced dispersal. Journal of the Royal Society Interface 9:1725-1732
Ministerio del Medio Ambiente de Colombia (2002) Programa Nacional para la Conservación de las Tortugas Marinas y Continentales de Colombia. Imprenta Nacional, Bogotá, Colombia 63 p.

Naro-Maciel E, Reid B, Fitzsimmons NN, Le M, DeSalle R, Amato G (2010). DNA barcodes for globally threatened marine turtles: a registry approach to documenting biodiversity. Molecular Ecology Resources 10(2):252-263

Rueda JV (2001) Programa nacional para la conservación de las tortugas marinas y continentales de Colombia (Propuesta para concertar plan estratégico para la recuperación de las especies Colombianas de fauna silvestre amenazadas y en vías de extinción). Ministerio del Medio Ambiente-Corpoguajira. Dirección General de Ecosistemas. Bogotá, Colombia 63 p.

Sarah V, Araújo F, Santos F (2009) DNA barcoding of Brazilian sea turtles (Testudines). Genetics and Molecular Biology 32(3):608-612

Saiki RK, Gelfand D, Stoffel S, Scharf S, Higurchi R, Horn G, Mulus K, Erlich H (1998) Pimer-directed enzymatic amplification of DNA with a thermostable DNA polymerase. Science 239:487-491

Sinniger F, Reimer J, Pawlowski J (2008) Potential of DNA Sequences to Identify Zoanthids (Cnidaria: Zoantharia). Zoological Science 25(12):1253-1260

Schander C, Willassen E (2005) What can biological barcoding do for Marine Biology? Marine Biology Research 1:79-83.

Stoeckle M (2003) Taxonomy, DNA, and the Barcode of Life. BioScience 53:796-797

Sujeevan R, Hebert PDN (2007) BARCODING BOLD: The Barcode of Life Data System (www. barcodinglife.org)

SWOT (2012) The state of the world's turtles. The world's most (and least) threatened sea turtles. SWOT Report VII. Arlington: SeaturtleStatus.org 7:48

Vincze T, Posfai J, Roberts R (2003) Nebcutter: a program to cleave DNA with restriction enzymes. Nucleic Acids Research. 31:3688-3691

Wang Z, Guo Y, He X, Liu C (2012) DNA barcoding of the fishes in South China Sea. Mitochondrial DNA 23(5):405-10. doi: 10.3109/19401736.2012.710204

Ward RD, Zemlak T, Innes B, Last B, Hebert P (2005) DNA barcoding Australia's fish species. Philosophical Transactions, Royal Society B 360:1847-57 
AMDAR y PCR extra-rápida para la identificación de la tortuga cabezona Caretta caretta (Testudines: Cheloniidae) utilizando el gen mitocondrial citocromo c oxidasa I (COI)

Resumen. Para identificación molecular de tortuga cabezona Caretta caretta; se utilizó Amplificación Mitocondrial DNA y Análisis de Restricción y PCR Extra-rápida. Se obtuvo muestras de sangre de juveniles de $C$. caretta de playa Don Diego (Magdalena; $n=4$ ) e Islas Del Rosario (Bolívar; $n=2$ ) en el Caribe colombiano. Se aisló DNA, se estandarizó la amplificación del gen mitocondrial citocromo c oxidasa I (COI) por PCR extra-rápida, obteniendo fragmentos de 650 pares de bases, disminuyendo en un tercio el tiempo de reacción. El producto amplificado de COI se analizó con enzimas HindIII, HpyCH4III y MseI generando perfil electroforético que al compararlo in silico con secuencias para otras especies de tortugas marinas; permitió identificar patrón específico para la tortuga cabezona. Las secuencias nucleótidicas se analizaron con BLAST y similaridad entre $97-99 \%$ con C. caretta en cinco secuencias y $92 \%$ en otra. La información de tortugas muestreadas fue integrada en base datos BOLD y se generó el código de barras. La metodología descrita para identificación de C. caretta es procedimiento rápido y bajo costo que minimiza el tiempo de PCR mejorando su especificidad.

Palabras clave: Caretta caretta; PCR extra-rápida; Citocromo c oxidasa I (COI); AMDAR; Código de barras.
AMDAR e PCR extra-rápida para a identificaçáo da Tartaruga-Comum Caretta caretta (Testudines: Cheloniidae), utilizando o gene mitocondrial citocromo c oxidase I (COI)

Resumo. Identificámos molecularmente a tartarugacomum Caretta caretta usando PCR amplificado de altavelocidade e análise de $\mathrm{ADN}$ mitocondrial restrito. Isolámos o ADN do sangue de juvenis $C$. carreta das praias Don Diego (Magdalena ; $\mathrm{n}=4$ ), das Ilhas del Rosario (Bolívas; n=2) no Caribe Colombiano. Ao utilizar a amplificação por PCR de alta velocidade da citocromo c oxidase I (COI ), reduzimos a reacção a um terço, e obtivemos fragmentos de 650 pares de bases. Analisámos o produto IOC amplificado com as enzimas de restrição HindIII , HpyCH4III e $M s e I$ e gerámos um perfil eletroforético, que comparado em silico com outras seqüências de espécies de tartarugas marinhas, revelou padrão específico à tartaruga-comum. Encontramos semelhanças entre 97-99\%, com C. caretta em cinco das seqüências de nucleotídeos BLAST analisados e 92\% com outro. Gerámos um código de barras para a informação e seqüências das tartaruga amostradas e foram armazenados na base de dados BOLD. A metodologia descrita para a identificação de C. caretta é um procedimento rápido e barato, que minimiza o tempo e melhora a especificidade da PCR.

Palavras-chave: Caretta caretta; PCR de alta velocidade; Citocromo c oxidase I ( COI); AMDAR; Código de barras. 